Article

\title{
Boosting the Activity and Stability of Copper Tungsten Nanoflakes toward Solar Water Oxidation by Iridium-Cobalt Phosphates Modification
}

\author{
Chao Li $\mathbb{D}$ and Peng Diao*iD \\ Key Laboratory of Aerospace Materials and Performance (Ministry of Education), School of Materials Science \\ and Engineering, Beihang University, Beijing 100191, China; ChaDli24@buaa.edu.cn \\ * Correspondence: pdiao@buaa.edu.cn; Tel.: +86-10-8233-9562
}

Received: 26 July 2020; Accepted: 7 August 2020; Published: 10 August 2020

check for updates

\begin{abstract}
Severe interfacial electron-hole recombination greatly limits the performance of $\mathrm{CuWO}_{4}$ photoanode towards the photoelectrochemical (PEC) oxygen evolution reaction (OER). Surface modification with an OER cocatalyst can reduce electron-hole recombination and thus improve the PEC OER performance of $\mathrm{CuWO}_{4}$. Herein, we coupled $\mathrm{CuWO}_{4}$ nanoflakes (NFs) with Iridium-cobalt phosphates (IrCo-Pi) and greatly improved the photoactivity of $\mathrm{CuWO}_{4}$. The optimized photocurrent density for $\mathrm{CuWO}_{4} / \mathrm{IrCo}-\mathrm{Pi}$ at $1.23 \mathrm{~V}$ vs. reversible hydrogen electrode (RHE) rose to $0.54 \mathrm{~mA} \cdot \mathrm{cm}^{-2}$, a ca. $70 \%$ increase over that of bare $\mathrm{CuWO}_{4}\left(0.32 \mathrm{~mA} \cdot \mathrm{cm}^{-2}\right)$. Such improved photoactivity was attributed to the enhanced hole collection efficiency, which resulted from the reduced charge-transfer resistance via IrCo-Pi modification. Moreover, the as-deposited IrCo-Pi layer well coated the inner $\mathrm{CuWO}_{4} \mathrm{NFs}$ and effectively prevented the photoinduced corrosion of $\mathrm{CuWO}_{4}$ in neutral potassium phosphate (KPi) buffer solution, eventually leading to a superior stability over the bare $\mathrm{CuWO}_{4}$. The facile preparation of $\mathrm{IrCo}-\mathrm{Pi}$ and its great improvement in the photoactivity make it possible to design an efficient $\mathrm{CuWO}_{4} /$ cocatalyst system towards PEC water oxidation.
\end{abstract}

Keywords: photoelectrochemical water oxidation; copper tungsten; iridium-cobalt phosphates; cocatalyst; interfaces

\section{Introduction}

Photoelectrochemical (PEC) water splitting is a green way to convert solar power into storable chemical fuels and thus addresses the rising demand for renewable energy [1,2]. The overall course includes both the oxygen evolution reaction (OER) and hydrogen evolution reaction (HER), which occur on the photoanode and photocathode, respectively [1]. Between them, the OER, with a more sluggish kinetic character, is generally considered as the rate-limiting step [3]. The solar-to-chemical conversion efficiency for PEC OER undoubtedly depends on the employed photoanode material. Beginning with $\mathrm{TiO}_{2}$ as an efficient photoanode in 1972 [4], some other binary transition-metal oxides, such as $\mathrm{ZnO}[5,6], \mathrm{WO}_{3}$ [7-10], and $\mathrm{Fe}_{2} \mathrm{O}_{3}$ [11-13], have been found active toward PEC OER. Among them, $\mathrm{WO}_{3}$ has attracted intensive attention due to its nontoxic composition, high hole mobility property $\left(\sim 10 \mathrm{~cm}^{2} \cdot \mathrm{V}^{-1} \cdot \mathrm{s}^{-1}\right)$ [14], and long hole diffusion length $(\sim 150 \mathrm{~nm})$ [14]. However, the drawbacks of $\mathrm{WO}_{3}$, such as relatively large bandgap (ca. $2.7 \mathrm{eV}$ ) [7-9] and narrow $\mathrm{pH}$ range for stable work $(\mathrm{pH}<4)$, restrict its large-scale application [15]. To address such limitations, it is feasible to associate another transition-metal oxide with $\mathrm{WO}_{3}$ to generate a $\mathrm{WO}_{3}$-based ternary oxide, as the introduced metallic component can regulate the bandgap structure and bonding state of $\mathrm{WO}_{3}$ without damaging its main merits [16-19].

In the family of $\mathrm{WO}_{3}$-based ternary oxides, $\mathrm{CuWO}_{4}$, as a promising photoanode material, has played an increasingly important role in PEC water oxidation over recent years [19-29]. Due to 
the contribution of $\mathrm{Cu}(3 \mathrm{~d})$ orbitals to the valance band, the bandgap value of $\mathrm{CuWO}_{4}$ is reduced by ca. $0.4 \mathrm{eV}$ compared to $\mathrm{WO}_{3}$, resulting in a red-shift of the optical-absorption edge from $475 \mathrm{~nm}$ to $550 \mathrm{~nm}$ [19]. While $\mathrm{WO}_{3}$ suffers severe corrosion in a $\mathrm{pH}>4$ aqueous solution due to its acidic oxide nature [15], $\mathrm{CuWO}_{4}$ exhibits excellent stability over a wider $\mathrm{pH}$ range $(\leq 9.5)$ [19-21,23-25,28,29]. The strong covalency of $\mathrm{Cu}-\mathrm{O}$ binding in $\mathrm{CuWO}_{4}$ inhibits the generation of soluble tungstate [19]. Despite these merits, $\mathrm{CuWO}_{4}$ still shows relatively lower photoactivity than the common photoanodes, including its binary counterpart $\mathrm{WO}_{3}$. Much effort has been directed to reveal the limiting factors in water oxidation for $\mathrm{CuWO}_{4}$ and then improve its solar-to-chemical conversion efficiency [24-29].

As reported previously, $\mathrm{CuWO}_{4}$ suffers from severe electron-hole recombination at the $\mathrm{CuWO}_{4} /$ solution interface owing to the slow OER kinetics $[21,22,27]$, thus limiting its PEC OER performance. However, in the presence of hole scavengers, such as $\mathrm{CH}_{3} \mathrm{OH}$ [19], $\mathrm{H}_{2} \mathrm{O}_{2}$ [25], or $\mathrm{Na}_{2} \mathrm{SO}_{3}$ [29], $\mathrm{CuWO}_{4}$ will show a much higher photoactivity, suggesting huge room for improvement in its PEC OER activity. Generally, surface modification with an OER cocatalyst is a valid method to alleviate the interfacial electron-hole recombination, since the cocatalyst can efficiently capture the photogenerated holes and then accelerate the PEC OER [5,8,30,31]. Nevertheless, Hamann [32] found that decorating $\mathrm{CuWO}_{4}$ with common cocatalysts usually led to comparable or even worse PEC performance. To date, the two previous studies concerning cocatalyst-modified $\mathrm{CuWO}_{4}$ reported that only mild enhancement in the photoactivity was achieved via manganese carbodiimide (MnNCN) [26] and manganese phosphate (Mn-Pi) [27] modification. Highly-enhanced performance can be potentially achieved via noble-metal-based OER catalysts, since they generally outperform the noble-metal-free counterparts whether as electrocatalysts alone or as cocatalysts combined with semiconductors [33]. However, the high cost prohibits their further application in industry.

Ir-Pi, with its noble-metal composition, shows the highest OER activity in the family of transition metal phosphate (TMP) [34]. Following the merit of TMP, IrPi is easy to prepare and possesses a superior stability in neutral potassium phosphate buffer solution (KPi) [34], both favoring its widespread applicability in OER. In our previous work, we doped the low-cost Co into pure Ir-Pi via a cyclic voltammetry (CV) co-deposition method, and the obtained Iridium-cobalt phosphates (IrCo-Pi) shows not only a reduced usage of Ir but also an enhanced OER activity over the pristine Ir-Pi due to the synergetic effect between Ir and Co [35]. Therefore, using IrCo-Pi to modify $\mathrm{CuWO}_{4}$ would be a possible approach to achieve a highly improved PEC OER performance for the $\mathrm{CuWO}_{4}$ photoanode while reducing the use of high-cost Ir.

Herein, we add IrCo-Pi on the surface of $\mathrm{CuWO}_{4}$ nanoflakes (NFs) via a facile CV co-deposition method to alleviate the interfacial charge recombination. The obtained $\mathrm{CuWO}_{4} / \mathrm{IrCo}-\mathrm{Pi}$ composites exhibit a highly-boosted PEC OER activity and an improved stability in neutral KPi solution over the bare $\mathrm{CuWO}_{4}$. We reveal that the greatly-enhanced hole-collection efficiency, which originates from the reduced charge-transfer resistance, accounts for the advanced PEC OER activity. The results presented here, as far as we know, stand as the best enhancement ever achieved on cocatalyst-modified $\mathrm{CuWO}_{4}$. This work demonstrates that it is feasible to design an efficient $\mathrm{CuWO}_{4} /$ cocatalyst system towards PEC water oxidation.

\section{Results and Discussion}

\subsection{Morphology, Chemical Composition, Crystal Structure and Bonding State of $\mathrm{CuWO}_{4}$ and $\mathrm{CuWO}_{4} / \mathrm{IrCo}-\mathrm{Pi}$}

As shown in Figure 1a,b, both $\mathrm{CuWO}_{4}$ and $\mathrm{CuWO}_{4} / \mathrm{IrCo}-\mathrm{Pi}$ exhibit similar network structures, suggesting that the deposition process imposed negligible impact on the morphology. Nevertheless, the roughening of the surface and the increase in the average thickness of nanoflakes (See the thickness distribution in Supplementary Figure S1a,b) reveal that a ca. $5 \mathrm{~nm}$-thick film has been deposited on

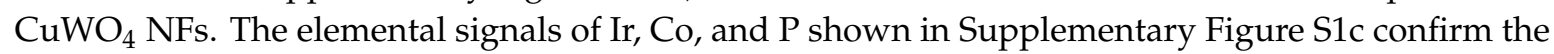
successful integration of $\mathrm{IrCo}-\mathrm{Pi}$ with $\mathrm{CuWO}_{4}$. Moreover, the three elements are evenly distributed throughout the entire NF (Figure 1c). Such a uniform distribution is attributed to the merit of CV 
co-deposition method, since it ensures a fast-alternate deposition of multiple components within a certain potential window [35]. The crystalline structures of $\mathrm{CuWO}_{4}$ and $\mathrm{CuWO} / \mathrm{IrCo}-\mathrm{Pi}$ are shown in Figure 1d,e. Well-resolved lattice fringes appear in both samples, and the lattice spaces of $0.376 \mathrm{~nm}$ and $0.487 \mathrm{~nm}$ are assigned to the (0-11) and (001) facet of triclinic $\mathrm{CuWO}_{4}$ phase, respectively. Moreover, the formation of a uniform amorphous IrCo-Pi layer outside the single-crystalline $\mathrm{CuWO}_{4}$ nanoflake proves the successful preparation of $\mathrm{CuWO}_{4} / \mathrm{IrCo}-\mathrm{Pi}$ composite, and the thickness of the layer (ca. $5 \mathrm{~nm}$ ) matches well the results shown in Supplementary Figure S1a,b. In line with the high-resolution transmission electron microscopy (HRTEM) tests, no signal of crystalline peaks related to IrCo-Pi was collected in the X-ray diffraction (XRD) patterns of $\mathrm{CuWO}_{4} / \mathrm{IrCo}-\mathrm{Pi}$ (Figure 1f) and FTO/IrCo-Pi (Supplementary Figure S1d).
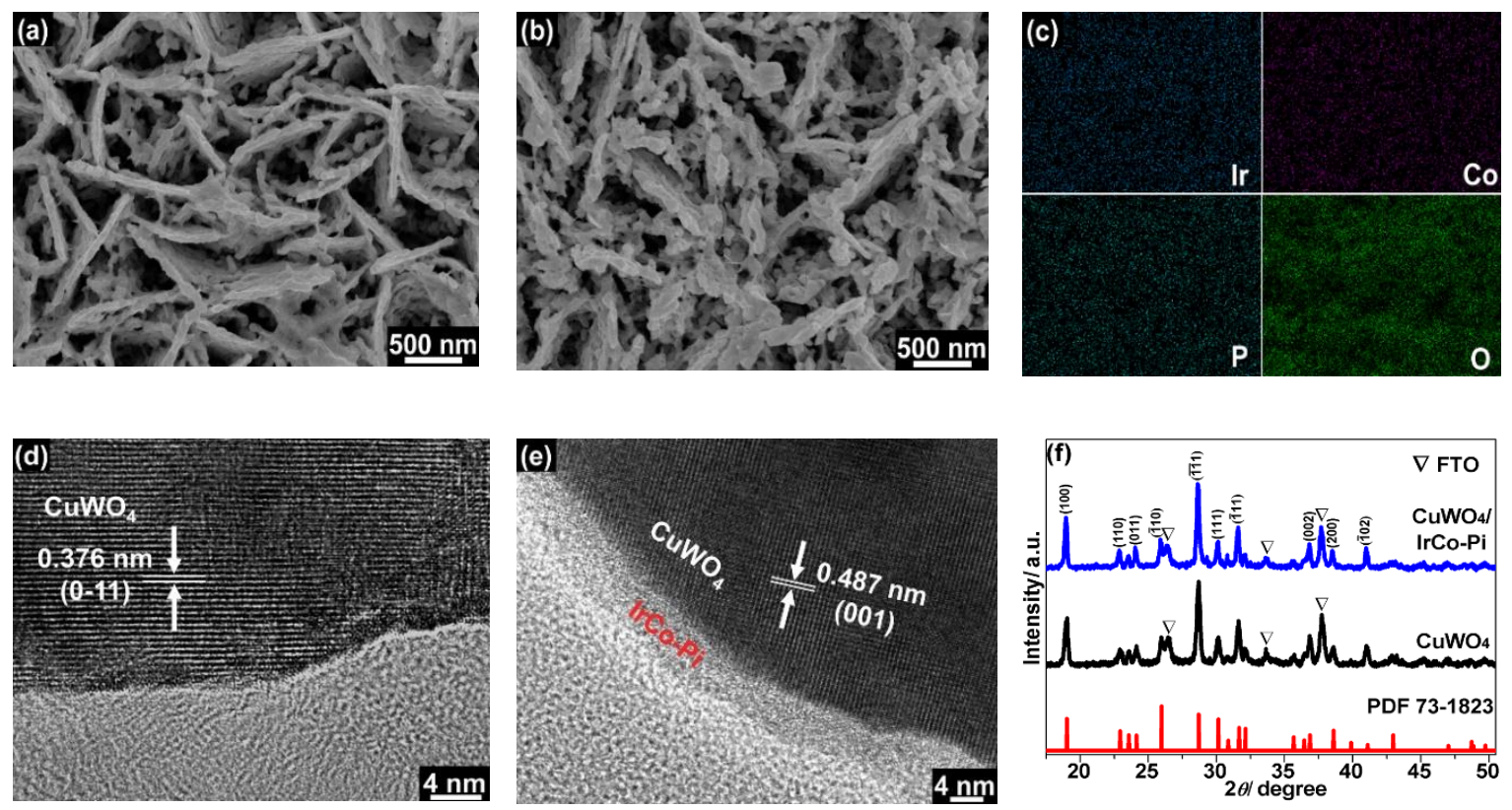

Figure 1. Typical top-view scanning electron microscope (SEM) images of (a) $\mathrm{CuWO}_{4}$ and (b) $\mathrm{CuWO}_{4} / \mathrm{IrCo}-\mathrm{Pi}$. (c) Energy dispersive spectrum (EDS) elemental mappings of Ir, Co, P and $\mathrm{O}$ in $\mathrm{CuWO}_{4} / \mathrm{IrCo}-\mathrm{Pi}$. HRTEM images of (d) $\mathrm{CuWO}_{4}$ and (e) $\mathrm{CuWO}_{4} / \mathrm{IrCo}-\mathrm{Pi}$. (f) XRD patterns of $\mathrm{CuWO}_{4}$ and $\mathrm{CuWO}_{4} / \mathrm{IrCo}-\mathrm{Pi}$.

X-ray photoelectron spectroscopic (XPS) measurements were conducted to explore the elemental constitutions and bonding states of $\mathrm{CuWO}_{4} / \mathrm{IrCo}-\mathrm{Pi}$ with different Ir-to-Co ratio (denoted as $R_{\mathrm{Ir}-\mathrm{to}-\mathrm{Co}}$ ). The obtained survey spectra in Supplementary Figure S2 reveal that $\mathrm{Cu}, \mathrm{W}, \mathrm{Ir}, \mathrm{Co}, \mathrm{P}$ and $\mathrm{O}$ are the major compositions of $\mathrm{CuWO}_{4} / \mathrm{IrCo}-\mathrm{Pi}$, further demonstrating the successful combination of IrCo-Pi with $\mathrm{CuWO}_{4}$. As shown above (Figure 1c), CV co-deposition enables the two elements (Ir and Co) to be uniformly mixed at the microscopic scale, which creates an environment in which synergistic effect between adjacent atoms can occur. To probe such issue, the high-resolution spectra of Co $2 \mathrm{p}$ and Ir $4 \mathrm{f}$ in $\mathrm{CuWO}_{4} / \mathrm{IrCo}-\mathrm{Pi}$ were examined, and the results are shown in Figure 2. All the Co-containing samples exhibit typical Co $2 \mathrm{p}^{1 / 2}$ (ca. $795.7 \mathrm{eV}$ ) and Co $2 \mathrm{p}^{3 / 2}$ (ca. $780.7 \mathrm{eV}$ ) peaks with the satellite peaks next to them, indicative of the co-existence of $\mathrm{Co}^{2+}$ and $\mathrm{Co}^{3+}[5,36]$, and the peak positions agree well with the previously-reported values [5,36,37]. As for Ir, the characteristic peaks of Ir $4 \mathrm{f}^{5 / 2}$ (ca. $65.4 \mathrm{eV}$ ) and Ir $4 \mathrm{f}^{7 / 2}$ (ca. $62.4 \mathrm{eV}$ ) are also presented in all the Ir-containing samples [34,35]. The mutual effect between Ir and $C o$ is reflected by the shift of peak position. In detail, the Co $2 p^{1 / 2}$ and Co $2 p^{3 / 2}$ peaks shift negatively with the increase of Ir contents, whereas the $\operatorname{Ir} 4 \mathrm{f}^{5 / 2}$ and $\operatorname{Ir} 4 \mathrm{f}^{7 / 2}$ peaks shift positively when the content of Co grows. The shift of the XPS peaks reveals a regional electron transfer from Ir to Co along the Ir-O-Co bond in IrCo-Pi, which accelerates the rate-limiting step of the OER for IrCo-Pi and 
finally results in an enhanced OER activity of IrCo-Pi over pristine Ir-Pi [35]. Further, the actual values of $R_{\text {Ir-to-Co }}$ were also quantified and the detailed results are summarized in Supplementary Table S1.

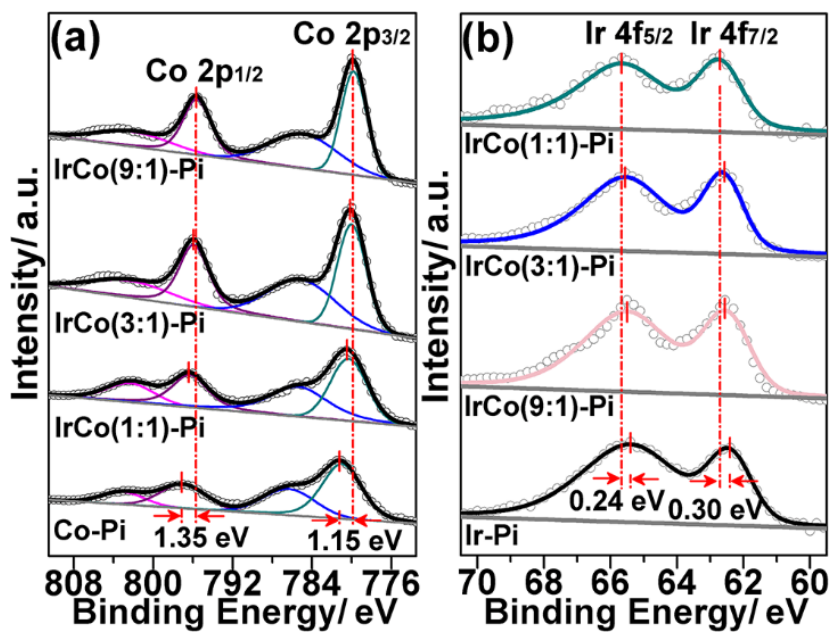

Figure 2. High-resolution XPS spectra of (a) Co 2p and (b) Ir 4 for $\mathrm{CuWO}_{4} / \mathrm{IrCo}$-Pi with different $R_{\text {Ir-to-Co }}$.

\subsection{Optical Absorption Property of $\mathrm{IrCo}-\mathrm{Pi}, \mathrm{CuWO}_{4}$ and $\mathrm{CuWO}_{4} / \mathrm{IrCo}-\mathrm{Pi}$}

Once an OER cocatalyst is deposited on a photoanode, it will cause the light scatter and absorption, and thereby inevitably influence the light-absorbing property of the photoanode [37,38]. Accordingly, a suitable cocatalyst should be as optically transparent as possible in the UV and visible-light regions. Herein, UV-vis measurements were carried out on all the samples. As shown in Figure 3a, IrCo-Pi only shows a light-grey color after 80 cycles of deposition, and its absorption intensity is negligible relative to that of $\mathrm{CuWO}_{4}$. Upon combination with IrCo-Pi (Figure 3b), all the $\mathrm{CuWO}$ /IrCo-Pi samples exhibit a nearly similar performance as bare $\mathrm{CuWO}_{4}$ in term of absorption intensity. The results above testify that IrCo-Pi, with its weak light absorption capacity, is an ideal OER cocatalyst candidate.
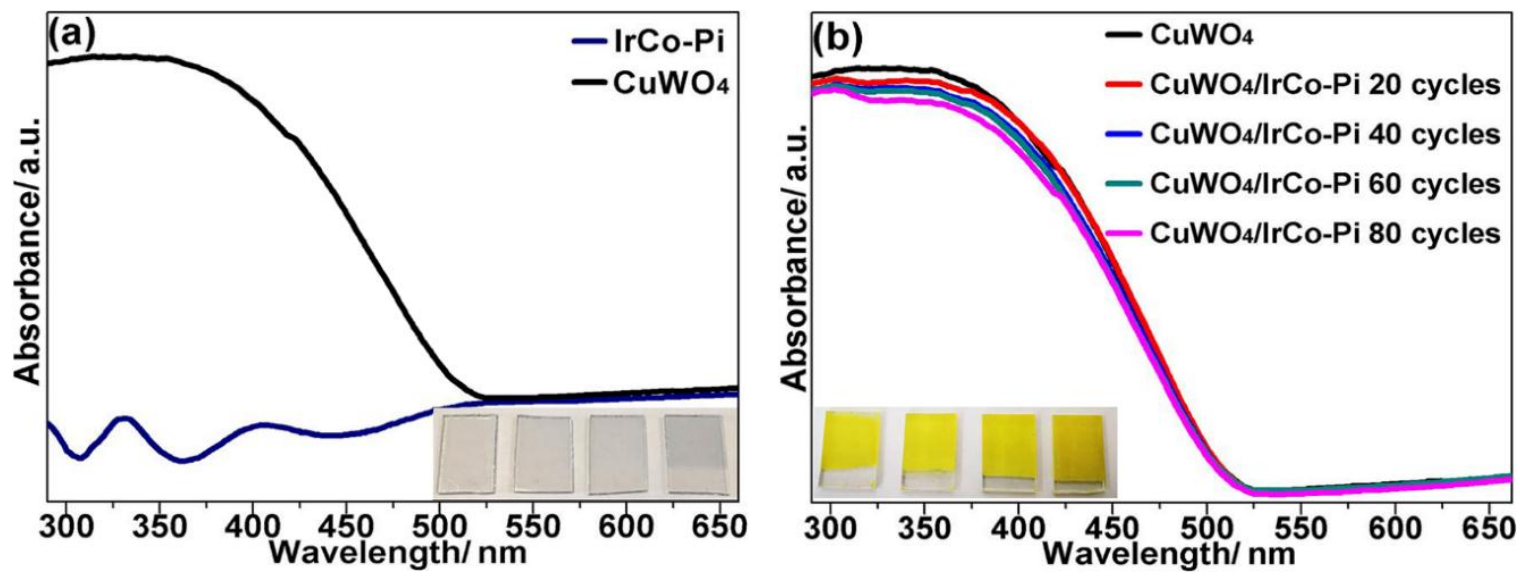

Figure 3. UV-vis absorption spectra of (a) $\mathrm{IrCo}_{-\mathrm{Pi}}$ and $\mathrm{CuWO}_{4}$, (b) $\mathrm{CuWO}_{4} / \mathrm{IrCo}-\mathrm{Pi}$ with varied deposition cycles. The insets in $(\mathbf{a}, \mathbf{b})$ show the optical images of $\mathrm{FTO} / \mathrm{IrCo}-\mathrm{Pi}$ and $\mathrm{CuWO}_{4} / \mathrm{IrCo}-\mathrm{Pi}$ with varied deposition cycles, respectively. (From left to right, 0, 40, 60, and 80 cycles).

\subsection{Photoactivity and Photostability of $\mathrm{CuWO}_{4}$ and $\mathrm{CuWO}_{4} / \mathrm{IrCo}$-Pi toward PEC OER}

The photocurrent density vs. applied potential $\left(\mathrm{Jph}_{\mathrm{ph}}-V\right)$ curves for $\mathrm{CuWO}_{4}$ and $\mathrm{CuWO}_{4} / \mathrm{IrCo}-\mathrm{Pi}$ with 30 deposition cycles are shown in Figure 4a. The relationship between the photocurrent density and deposition cycle are shown in Supplementary Figure S3. Given that the dark current density $\left(J_{\text {dark }}\right)$ for $\mathrm{CuWO}_{4} / \mathrm{IrCo}-\mathrm{Pi}$ is no longer inappreciable over the whole potential range (see Supplementary 
Figure $S 4 \mathrm{a}, \mathrm{b}), J_{\mathrm{ph}}$ herein is the photocurrent density obtained by deducting $J_{\text {dark }}$ from the total $\left(J_{\text {total }}\right)$ under illumination. As shown, Co-Pi only brings about mild improvement in PEC performance while obvious enhancement is obtained via Ir-Pi modification, revealing that Ir-Pi has a much higher activity as an OER cocatalyst than Co-Pi. Although the increased proportion of Ir-Pi in IrCo-Pi hybrids leads to better enhancement effect, such an effect does not merely increase monotonically with the growth of $R_{\text {Ir-to-Co, }}$ on the ground that the mutual effect between Ir and Co can enhance the inherent activity of IrCo-Pi [35]. When Ir-Pi gradually becomes the main composition in IrCo-Pi hybrids (the nominal and actual $R_{\text {Ir-to-Co }}$ exceed 5:1 and 1:1, respectively, see Supplementary Table S1), IrCo-Pi starts to outperform Ir-Pi. The optimized $R_{\text {Ir-to-Co }}$ is 9:1 under which the mutual effect is demonstrated to be the strongest due to the nearly 1:1 ratio of Ir-to-Co [35].
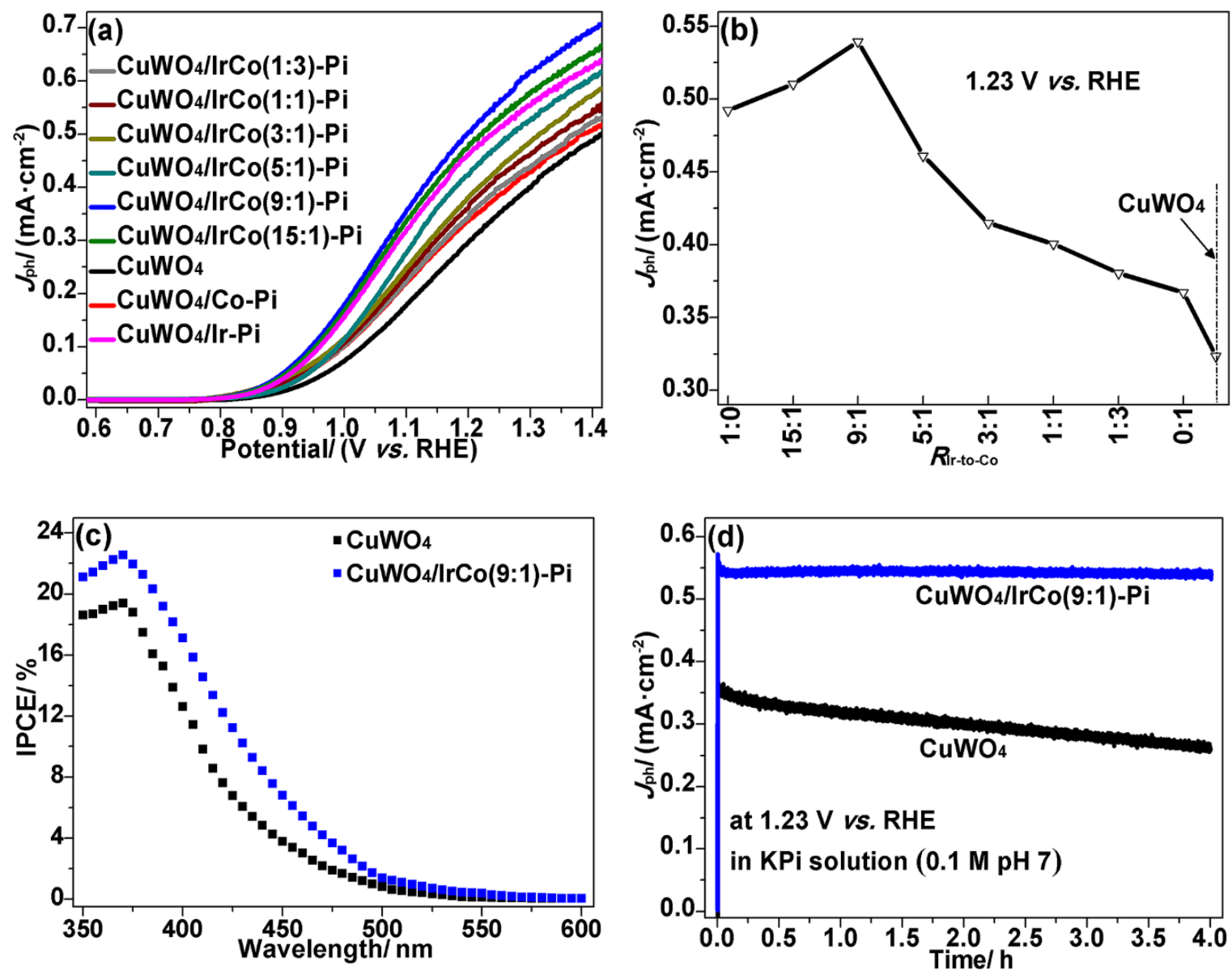

Figure 4. (a) $J_{\mathrm{ph}}-V$ curves of $\mathrm{CuWO}_{4}$ and $\mathrm{CuWO}_{4} / \mathrm{IrCo}-\mathrm{Pi}$ with different $R_{\mathrm{Ir}-\text { to-Co}}$. (b) $J_{\mathrm{ph}}$ at $1.23 \mathrm{~V}$ vs. RHE for $\mathrm{CuWO}_{4}$ and $\mathrm{CuWO}_{4} / \mathrm{IrCo}-\mathrm{Pi}$ with different $R_{\text {Ir-to-Co. }}$ (c) IPCE of $\mathrm{CuWO}_{4}$ and $\mathrm{CuWO}_{4} / \mathrm{IrCo}(9: 1)-\mathrm{Pi}$ at $1.23 \mathrm{~V}$ vs. RHE over the wavelength range from $350 \mathrm{~nm}$ to $600 \mathrm{~nm}$. (d) Current density-time responses of $\mathrm{CuWO}_{4}$ and $\mathrm{CuWO}_{4} / \mathrm{IrCo}(9: 1)-\mathrm{Pi}$ at $1.23 \mathrm{~V}$ vs. RHE under continuous illumination.

As shown in Figure $4 \mathrm{~b}$, with the aid of IrCo-Pi with the optimized $R_{\text {Ir-to-Co }}$ (hereafter, denoted as $\operatorname{IrCo}(9: 1)-\mathrm{Pi})$, the photocurrent density at $1.23 \mathrm{~V}$ vs. RHE rises to $0.54 \mathrm{~mA} \cdot \mathrm{cm}^{-2}$, a ca. $70 \%$ increase over that of $\mathrm{CuWO}_{4}\left(0.32 \mathrm{~mA} \cdot \mathrm{cm}^{-2}\right)$. However, no obvious shift of the OER onset potential is observed, which is also found in other reports on cocatalyst-modified $\mathrm{CuWO}_{4}$ [26,39-41]. This indicates that the charge-transfer resistance around the onset potential range is quite large and thus even an OER cocatalyst fails to effectively accelerate the charge transfer. The comparison between our study and previous ones has been made and the results are summarized in Table 1. We can see that the results herein represent the highest level ever achieved on cocatalyst-modified single-phase 
$\mathrm{CuWO}_{4}$. Note that, in Ref. [40,41], although the authors named the photoanode $\mathrm{CuWO}_{4}$, it actually was, as the authors mentioned in the articles, a mixture of $\mathrm{WO}_{3}$ and $\mathrm{CuWO}_{4}$ based on the XRD data where unique $\mathrm{WO}_{3}$ peaks at ca. $33.2^{\circ}$ can be clearly seen. According to the prior study, in a cocatalyst-modified $\mathrm{WO}_{3} / \mathrm{CuWO}_{4}$ composite system, $\mathrm{WO}_{3}$ contributes largely to the shift in the photocurrent density [27]. Besides, the incident photon-to-current efficiency (IPCE) data in Figure 4c show that $\mathrm{CuWO}_{4} / \mathrm{IrCo}(9: 1)$-Pi exhibits higher values than $\mathrm{CuWO}_{4}$ within the whole wavelength range, signifying that it can convert the incident light more efficiently.

Table 1. PEC OER performances of cocatalyst-modified $\mathrm{CuWO}_{4}$ or $\mathrm{WO}_{3} / \mathrm{CuWO}_{4}$ photoanodes in this work and previous literatures [26,27,39-41].

\begin{tabular}{cccccc}
\hline \multirow{2}{*}{ Reference } & \multirow{2}{*}{ Photoanode } & Cocatalyst & \multicolumn{2}{c}{$J_{\mathbf{p h}}\left(\mathbf{m A} \cdot \mathbf{c m}^{-2}\right)$ at 1.23 V vs. RHE } \\
\cline { 4 - 6 } & & Before & After & Increment \\
\hline This work & $\mathrm{CuWO}_{4}$ & $\mathrm{IrCo}(9: 1)-\mathrm{Pi}$ & 0.32 & 0.54 & $70 \%$ \\
This work & $\mathrm{CuWO}_{4}$ & $\mathrm{Ir}-\mathrm{Pi}$ & 0.32 & 0.50 & $56 \%$ \\
{$[26]$} & $\mathrm{CuWO}_{4}$ & $\mathrm{MnNCN}$ & 0.022 & 0.03 & $36 \%$ \\
{$[27]$} & $\mathrm{CuWO}_{4}$ & $\mathrm{Mn}-\mathrm{Pi}$ & 0.058 & 0.075 & $29 \%$ \\
{$[39]$} & $\mathrm{WO}_{3} / \mathrm{CuWO}_{4}$ & $\mathrm{Mn}-\mathrm{Pi}$ & 0.38 & 0.58 & $50 \%$ \\
{$[40]$} & $\mathrm{WO}_{3} / \mathrm{CuWO}_{4}$ & $\mathrm{Co}-\mathrm{Pi}$ & 0.20 & 0.37 & $85 \%$ \\
{$[41]$} & $\mathrm{WO}_{3} / \mathrm{CuWO}_{4}$ & $\mathrm{Ni}-\mathrm{Pi}$ & 0.40 & 0.60 & $50 \%$ \\
\hline
\end{tabular}

The intensity of the incident light is $100 \mathrm{~mW} \cdot \mathrm{cm}^{-2}$. The electrolyte used in this work and all the cited references is $0.1 \mathrm{M} \mathrm{KPi}$ solution with a $\mathrm{pH}$ value of 7 .

By comparing the results herein with those in our previous work [35], we find that the optimized $R_{\text {Ir-to-Co }}$ would vary based on the number of deposition circles, the substrates for deposition. Despite this, we still would like to highlight that IrCo-Pi, with its ease of preparation, reduced usage of high-cost Ir and superior performance over pure Ir-Pi, can enrich the photoanode/cocatalyst systems.

The stability during solar water oxidation is another vital factor to evaluate a photoanode. Herein, the long-term durability tests were conducted on both $\mathrm{CuWO}_{4}$ and $\mathrm{CuWO}_{4} / \operatorname{IrCo}(9: 1)-\mathrm{Pi}$ in a neutral KPi solution. As shown in Figure $4 \mathrm{~d}, \mathrm{CuWO}_{4} / \mathrm{IrCo}(9: 1)$-Pi shows a higher photocurrent density than $\mathrm{CuWO}_{4}$, manifesting that IrCo-Pi improves the PEC OER activity of $\mathrm{CuWO}_{4}$. Over a 4-h continuous illumination, $\mathrm{CuWO}_{4}$ reveals a medium decrease in the photocurrent density, consistent with the prior reports where $\mathrm{CuWO}_{4}$ is demonstrated to be slightly unstable in KPi solution [19,21,28]. This instability is closely related to the phosphate anion, not $\mathrm{pH}$ [21]. Upon using a potassium borate (KBi) solution (same $\mathrm{pH}$ and concentration), $\mathrm{CuWO}_{4}$ would display a superior photostability (See Figure S4c) [21,28,29]. CuWO $/ \mathrm{IrCo}(9: 1)-\mathrm{Pi}$, in contrast, shows a nearly constant photocurrent density under the same conditions. The enhanced stability can be ascribed to the two following reasons: First, the as-deposited IrCo-Pi layer well coats $\mathrm{CuWO}_{4}$ (see Figure $1 \mathrm{~b}, \mathrm{e}$ ) and then prevents the photoinduced corrosion of $\mathrm{CuWO}_{4}$ in $\mathrm{KPi}$ solution. Second, IrCo-Pi itself shows an excellent stability in $\mathrm{KPi}$ solution [35], ensuring long-term protection of the inner $\mathrm{CuWO}_{4} \mathrm{NFs}$.

\subsection{Interfacial Charge-Transfer Behavior of $\mathrm{CuWO}_{4}$ and $\mathrm{CuWO} / / \mathrm{IrCo}-\mathrm{Pi}$}

The primary aim of IrCo-Pi modification is to reduce the interfacial electron-hole recombination. Herein, photocurrent transient measurements were conducted on $\mathrm{CuWO}_{4}$ and $\mathrm{CuWO}_{4} / \mathrm{IrCo}(9: 1)-\mathrm{Pi}$ under chopped illumination to study such recombination. As shown in Figure 5a and Supplementary Figure S5a, sharp anodic/cathodic photocurrent spikes appear on both samples when the light is suddenly on or off, indicative of interfacial charge recombination [42-44]. In detail, upon illumination, the photoinduced holes transport to the $\mathrm{CuWO}_{4} /$ solution interface and then charge the surface states (non-Faradaic current) or oxidize $\mathrm{H}_{2} \mathrm{O}$ (Faradaic current) [44-47]. Both procedures contribute to the initial anodic current. Then the non-Faradaic current decays rapidly owing to the electron-hole recombination $[46,47]$. Therefore, water oxidation finally dominates the whole process and the steady-state current density agrees well with the value shown in $J-V$ curves (See Figure 4a) [47]. 
When the light is off, the trapped holes at the surface states would be reduced by the electrons, giving rise to the cathodic spike [42,43]. The current eventually decreases to ca. $0 \mathrm{~mA} \cdot \mathrm{cm}^{-2}$, since no reaction occurs at this potential without illumination (see Supplementary Figure S4a). The charge-recombination rate can be reflected by the decay time $(D)$ of the transient spike, which is calculated via the following equation [42]:

$$
D=\left(I_{\mathrm{t}}-I_{\mathrm{s}}\right) /\left(I_{\text {in }}-I_{\mathrm{s}}\right)
$$

where $I_{\mathrm{t}}$ is the current at time $t, I_{\mathrm{s}}$ is the steady-state current, and $I_{\text {in }}$ is the initial spike current. The time $t$ at which In $D=-1$ is generally used to evaluate and compare the transient decay time $[42,43,46]$. As seen from Figure $5 b, \mathrm{CuWO}_{4} / \mathrm{IrCo}(9: 1)$-Pi shows a relatively longer decay time than bare $\mathrm{CuWO}_{4}$, suggesting a lower electron-hole recombination rate for $\mathrm{CuWO}_{4} / \mathrm{IrCo}(9: 1)-\mathrm{Pi}$. This can be ascribed to the fact that the photogenerated holes can be efficiently captured by IrCo-Pi and then quick consumed in OER catalyzed by IrCo-Pi. Accordingly, the presence of $\mathrm{IrCo}-\mathrm{Pi}$ on the surface of $\mathrm{CuWO}_{4}$ significantly accelerates the separation of photoinduced electron-hole pairs and hence boosts the performance for PEC OER.
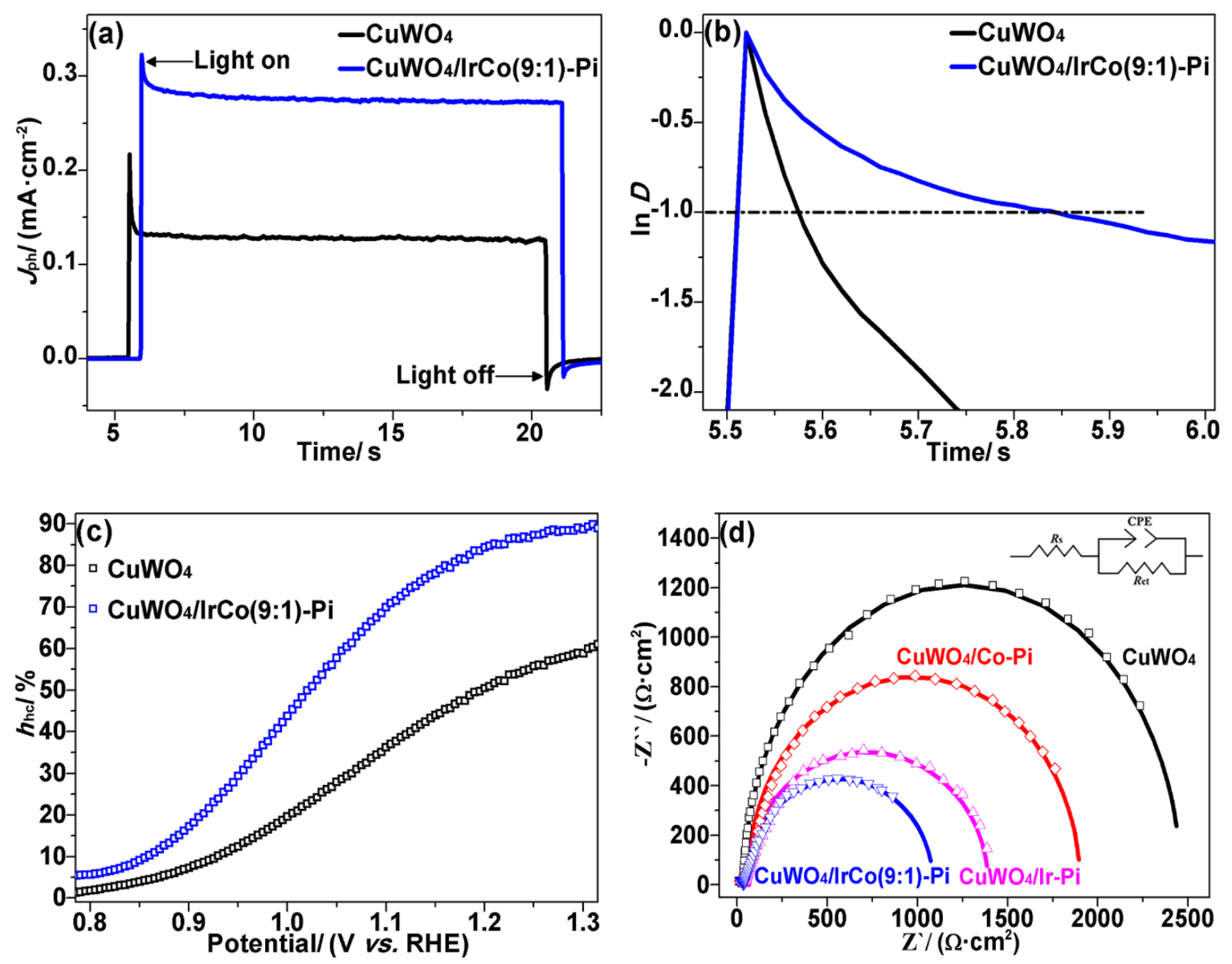

Figure 5. (a) Transient photocurrent density curves for $\mathrm{CuWO}_{4}$ and $\mathrm{CuWO}_{4} / \mathrm{IrCo}(9: 1)-\mathrm{Pi}$ at $1.05 \mathrm{~V}$ vs. RHE for one light-on/light-off cycle. (b) The corresponding transient decay time for each photoanode. (c) $\eta_{\mathrm{hc}}$ for $\mathrm{CuWO}_{4}$ and $\mathrm{CuWO}_{4} / \mathrm{IrCo}(9: 1)-\mathrm{Pi}$. (d) Nyquist plots of bare $\mathrm{CuWO}_{4}, \mathrm{CuWO}_{4} / \mathrm{Co}-\mathrm{Pi}$, $\mathrm{CuWO}_{4} / \mathrm{Ir}-\mathrm{Pi}$ and $\mathrm{CuWO}_{4} / \mathrm{IrCo}(9: 1)-\mathrm{Pi}$ at $1.05 \mathrm{~V}$ vs. RHE within the frequency range of $10^{-1}-10^{4} \mathrm{~Hz}$ under illumination. The inset is the corresponding equivalent circuit.

To quantify the hole-collection efficiency $\left(\eta_{\mathrm{hc}}\right)$ at the $\mathrm{CuWO}_{4} /$ solution interface, PEC measurements were carried out in the presence of hole scavenger $\mathrm{Na}_{2} \mathrm{SO}_{3}$, which can consume the photogenerated holes rapidly and thus improve $\eta_{\mathrm{hc}}$ to ca. $100 \%$ [48]. Due to the nearly complete suppression of 
surface recombination, $J-V$ curve for $\mathrm{Na}_{2} \mathrm{SO}_{3}$ oxidation (Supplementary Figure S5b) displays a more negative OER onset potential and a much higher photocurrent density over the whole potential window. Accordingly, $\eta_{\mathrm{hc}}$ is defined by the following equation [48]:

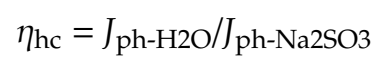

where $J_{\mathrm{ph}-\mathrm{H} 2 \mathrm{O}}$ and $J_{\mathrm{ph}-\mathrm{Na} 2 \mathrm{SO} 3}$ refer to the photocurrent density for $\mathrm{H}_{2} \mathrm{O}$ and $\mathrm{Na}_{2} \mathrm{SO}_{3}$ oxidation, respectively. As shown in Figure $5 \mathrm{c}$, although $\eta_{\mathrm{hc}}$ gradually increases with the applied potential, it only shows a value of ca. $55 \%$ even at $1.23 \mathrm{~V}$ vs. RHE, indicating that near half of the photogenerated holes on the surface are consumed via the useless recombination. With $\operatorname{IrCo}(9: 1)$-Pi modification, $\eta_{\mathrm{hc}}$ is apparently improved in the whole potential range and shifts to ca. $90 \%$ at $1.23 \mathrm{~V}$ vs. RHE, suggesting that the vast majority of photogenerated holes are captured by IrCo-Pi and then participate the OER.

Electrochemical impedance spectroscopy (EIS) measurements were conducted under illumination to explore the reasons for the enhanced photoactivity. As shown in Figure 5d, only one semicircle is presented for both the bare $\mathrm{CuWO}_{4}$ and cocatalyst-modified $\mathrm{CuWO}_{4}$, therefore, a simple but typical Randel's circuit (inset in Figure 5d) was used to interpret the obtained EIS data $[21,40,41,49,50]$. The equivalent circuit consists of the series resistance $\left(R_{\mathrm{s}}\right)$, the constant phase element $(C P E)$ and the charge-transfer resistance $\left(R_{\mathrm{ct}}\right)$. The fitting results are summarized in Supplementary Table S2. Among all the samples, $\mathrm{CuWO}_{4} / \operatorname{IrCo}(9: 1)$-Pi exhibits the smallest $R_{\mathrm{ct}}$ value (ca. $1114 \Omega \cdot \mathrm{cm}^{2}$ ), suggesting the fastest interfacial charge-transfer kinetics. The reduced charge-transfer barrier can boost the electron-hole separation on the surface and thus reduce the useless recombination, finally leading to an enhanced hole-collection efficiency.

\subsection{The Interfacial Charge-Transfer Process for $\mathrm{CuWO}_{4} / \mathrm{IrCo}-\mathrm{Pi}$}

The charge-transfer process at the photoanode/solution interface for $\mathrm{CuWO}_{4} / \mathrm{IrCo}(9: 1)-\mathrm{Pi}$ is illustrated in Figure 6. Upon illumination, holes are generated in the valence band of $\mathrm{CuWO}_{4}$ located at ca. $2.80 \mathrm{~V}$ vs. RHE [22], and hence they have sufficient driving force to oxidize $\mathrm{Co}^{2+}$ and $\mathrm{Ir}^{3+}$ to $\mathrm{Co}^{3+/ 4+}$ and $\mathrm{Ir}^{4+/ 5+}$, respectively $[34,36]$. Both the $\mathrm{Co}^{2+}$ and $\mathrm{Ir}^{3+}$ oxidation via photogenerated holes are kinetically faster than the direct $\mathrm{H}_{2} \mathrm{O}$ oxidation, and therefore the holes are transferred rapidly with the aid of IrCo-Pi and the electron-hole recombination is suppressed effectively. The obtained $\mathrm{Co}^{3+/ 4+}$ and $\mathrm{Ir}^{4+/ 5+}$ show high activity toward OER $[34,36]$, and importantly, they would be reduced back to $\mathrm{Co}^{2+}$ and $\mathrm{Ir}^{3+}$ as the OER proceeds. Such oxidation-reduction cycle ensures a lasting enhancement effect in the photoactivity via IrCo-Pi. Therefore, through an alternative IrCo-Pi involved pathway for photoinduced holes, the interfacial charge recombination is considerably reduced, leading to an enhanced hole collection efficiency and an eventually improved photoactivity.

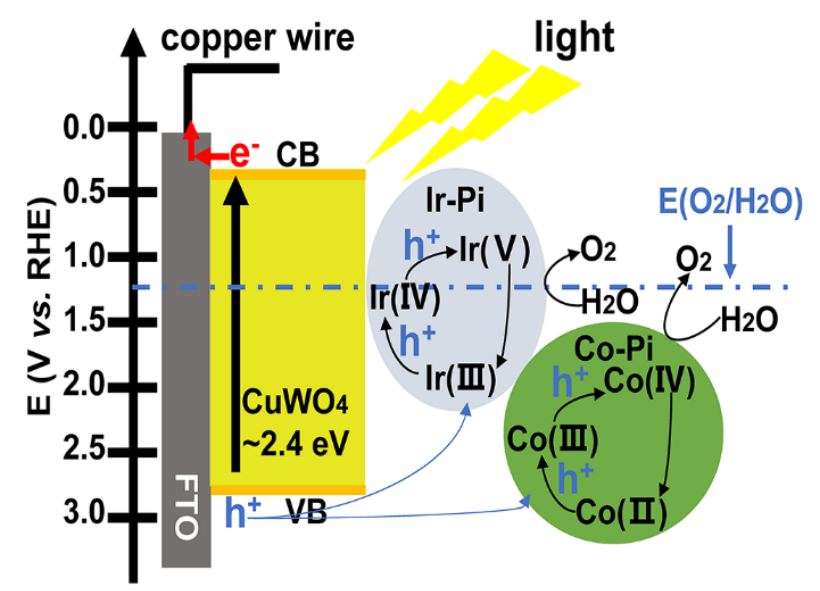

Figure 6. The schematic illustration of the charge-transfer pathway at the photoanode/solution interface for $\mathrm{CuWO}_{4} / \mathrm{IrCo}-\mathrm{Pi}$. 


\section{Materials and Methods}

\subsection{Chemicals and Substrates}

Tungstic acid $\left(\mathrm{H}_{2} \mathrm{WO}_{4}\right)$, polyvinyl alcohol $\left(\left(\mathrm{C}_{2} \mathrm{H}_{4} \mathrm{O}\right)_{n}\right)$, hydrogen peroxide $\left(\mathrm{H}_{2} \mathrm{O}_{2}\right)$, acetonitrile $\left(\mathrm{C}_{2} \mathrm{H}_{3} \mathrm{~N}\right)$, urea $\left(\mathrm{H}_{2} \mathrm{NCONH}_{2}\right)$, oxalic acid $\left(\mathrm{H}_{2} \mathrm{C}_{2} \mathrm{O}_{4}\right)$, hydrochloric acid $(\mathrm{HCl})$, and acetic acid $\left(\mathrm{C}_{2} \mathrm{H}_{4} \mathrm{O}_{2}\right)$ were purchased from Beijing Chemical Works. Cupric nitrate trihydrate $\left(\mathrm{Cu}\left(\mathrm{NO}_{3}\right)_{2} \cdot 3 \mathrm{H}_{2} \mathrm{O}\right)$ was purchased from Sinopharm Chemical Reagent Co., Ltd. Cobalt(II) chloride hexahydrate $\left(\mathrm{CoCl}_{2} \cdot 6 \mathrm{H}_{2} \mathrm{O}\right.$, $99.9 \%$ ), iridium(III) chloride hydrate $\left(\mathrm{IrCl}_{3} \cdot \mathrm{xH}_{2} \mathrm{O}, 99.9 \%\right)$, potassium dihydrogen phosphate $\left(\mathrm{KH}_{2} \mathrm{PO}_{4}\right.$, 99.5\%), and dipotassium hydrogen phosphate $\left(\mathrm{K}_{2} \mathrm{HPO}_{4}, 99.5 \%\right)$ were purchased from Alfa Aesar Chemicals (Co., Ltd. Shanghai, China). Fluorine-doped tin oxide (FTO) substrates $\left(8 \Omega \cdot \mathrm{cm}^{2}\right.$, transmittance of $80 \%$ ) were purchased from Asahi Glass (Co., Ltd. Tokyo, Japan). All the chemicals used herein were of analytical grade without further purification. All the aqueous solutions herein were prepared using deionized water $(18 \mathrm{M} \Omega \cdot \mathrm{cm})$.

\subsection{Preparation of $\mathrm{CuWO}_{4}$ and $\mathrm{CuWO}_{4} / \mathrm{IrCo}-\mathrm{Pi}$}

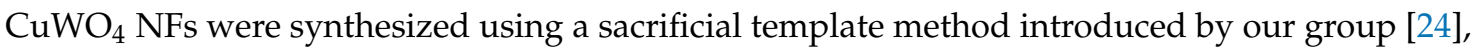
where $\mathrm{WO}_{3} \mathrm{NFs}$ prepared via a reported hydrothermal approach [7] served as the templates. IrCo-Pi was coupled with $\mathrm{CuWO}_{4}$ NFs via a CV co-deposition method within a potential window from $0.65 \mathrm{~V}$ to $1.85 \mathrm{~V}$ vs. RHE at a scan rate of $0.05 \mathrm{~V} \cdot \mathrm{s}^{-1}$ for different cycles. The solution for deposition consisted of $0.1 \mathrm{M} \mathrm{KH}_{2} \mathrm{PO}_{4} / \mathrm{K}_{2} \mathrm{HPO}_{4}(\mathrm{KPi})(\mathrm{pH} 7)$ and a $0.5 \mathrm{mM}$ mixture of $\mathrm{CoCl}_{2}$ and $\mathrm{IrCl}_{3}$. The nominal molar ratio of Ir to $\mathrm{Co}\left(R_{\mathrm{Ir}-\mathrm{to}-\mathrm{Co}_{\mathrm{o}}}\right)$ was altered within a predefined range. For convenience, $R_{\mathrm{Ir}-\mathrm{to}-\mathrm{Co}_{\mathrm{o}}}=1: 0$ or 0:1 refers to pure Ir-Pi or Co-Pi, respectively.

\subsection{Characterization}

X-ray diffraction (XRD) data were recorded by a D/MAX-2500 advance powder X-ray diffractometer (Rigaku Co., Tokyo, Japan) with $\mathrm{Cu} \mathrm{K} \alpha$ radiation. High-resolution transmission electron microscopy (HRTEM) data were collected by a field emission JEM-2100F microscope (JEOL Ltd., Tokyo, Japan) under an accelerating voltage of $200 \mathrm{kV}$. The morphologies and elemental compositions were analyzed using a S-4800 field emission scanning electron microscope (FESEM) (Hitachi Ltd., Tokyo, Japan) equipped with an energy dispersive $X$-ray analysis (EDXA) system under an accelerating voltage of $5 \mathrm{kV}$. UV-vis diffuse reflection spectra were gathered via a $3600 \mathrm{UV}$-vis-NIR spectrophotometer (Shimadzu Co., Kyoto, Japan). X-ray photoelectron spectroscopic (XPS) spectra were recorded via an Escalab 250Xi (Thermo Fisher Scientific Co., Waltham, MA, USA) using an Al-monochromatic X-ray with a power of $200 \mathrm{~W}$. All the binding energies herein have been calibrated against C $1 \mathrm{~s}$ at $284.8 \mathrm{eV}$.

\subsection{Electrochemical and PEC Measurements}

All the electrochemical and PEC measurements were carried out on a CHI 660E work station $(\mathrm{CH}$ Instruments Co., Austin, TX, USA) equipped with a three-electrode configuration. The bare $\mathrm{CuWO}_{4}$ or $\mathrm{CuWO}_{4} /$ cocatalyst, a Pt mesh, and a saturated calomel electrode (SCE) acted as the working, auxiliary, and reference electrode, respectively. A $300 \mathrm{~W}$ Xe lamp equipped with an AM 1.5 G filter (PLS-SXE300, Beijing Perfectlight Co., Ltd. Beijing, China) was employed as the light source. The samples were immersed into the electrolyte with a contact area of $0.21 \mathrm{~cm}^{2}$ under front-side illumination and the light intensity was to $100 \mathrm{~mW} \cdot \mathrm{cm}^{-2}$. The impedance spectra obtained in the electrochemical impedance spectroscopy (EIS) tests were fitted and analyzed via Zview software. The data of incident photon-to-current efficiency (IPCE) were obtained by recording the current density at $1.23 \mathrm{~V}$ vs. RHE under a certain monochromatic light (wavelength range: 350-600 nm, step: $5 \mathrm{~nm}$ ). The detailed values were calculated via Equation (3) below [51]:

$$
\operatorname{IPCE}=(1240 J) /\left(\lambda I_{\text {light }}\right) \times 100 \%
$$


where $\lambda$ is the wavelength of the incident light $(\mathrm{nm}), J$ is the current density $\left(\mathrm{mA} \cdot \mathrm{cm}^{-2}\right)$ under a certain monochromatic light, and $I_{\text {light }}$ is the intensity of the incident light $\left(\mathrm{mW} \cdot \mathrm{cm}^{-2}\right)$. The electrolyte was a $0.1 \mathrm{M} \mathrm{KPi}$ buffer solution ( $\mathrm{pH} 7$ ) with or without adding $0.1 \mathrm{M} \mathrm{Na}_{2} \mathrm{SO}_{3}$. All potentials herein were against SCE and converted to RHE via the Equation (4) below [24]:

$$
E_{\mathrm{RHE}}=E_{\mathrm{SCE}}+0.059^{*} \mathrm{pH}+0.244
$$

\section{Conclusions}

In summary, IrCo-Pi was electrodeposited on $\mathrm{CuWO}_{4} \mathrm{NFs}$ to alleviate the interfacial electron-hole recombination and thereby enhance the photoactivity of $\mathrm{CuWO}_{4}$. After the $\mathrm{CuWO}_{4} \mathrm{NFs}$ are modified with $\operatorname{IrCo}(9: 1)-\mathrm{Pi}$, the photocurrent density of the obtained composite photoanode at $1.23 \mathrm{~V}$ vs. RHE increases from $0.32 \mathrm{~mA} \cdot \mathrm{cm}^{-2}$ to $0.54 \mathrm{~mA} \cdot \mathrm{cm}^{-2}$. Such an improvement stands as the highest level ever achieved on cocatalyst-modified single-phase $\mathrm{CuWO}_{4}$. The high photoactivity is attributed to the greatly enhanced hole collection efficiency, which results from the reduced interfacial charge-transfer resistance. In addition, $\mathrm{CuWO} 4 / \mathrm{IrCo}(9: 1)$-Pi exhibits a superior photostability in neutral KPi solution over the bare $\mathrm{CuWO}_{4}$. This work reveals that it is feasible to obtain a highly-enhanced PEC OER performance for $\mathrm{CuWO}_{4}$ via cocatalyst modification.

Supplementary Materials: The following are available online at http://www.mdpi.com/2073-4344/10/8/913/s1, Figure S1: The detailed thickness distribution of (a) $\mathrm{CuWO}_{4} \mathrm{NFs}$ and (b) $\mathrm{CuWO}_{4} / \mathrm{IrCo}-\mathrm{Pi} \mathrm{NFs}$. (c) EDS spectrum of $\mathrm{CuWO}_{4} / \mathrm{IrCo}-\mathrm{Pi}$. (d) XRD patterns of FTO, FTO/Co-Pi, FTO/Ir-Pi, and FTO/IrCo-Pi, Figure S2: XPS survey of (a) $\mathrm{CuWO}_{4} / \mathrm{Co}-\mathrm{Pi}$ (b) $\mathrm{CuWO}_{4} / \mathrm{IrCo}-\mathrm{Pi}$ and (c) $\mathrm{CuWO}_{4} / \mathrm{Ir}$-Pi, Figure S3: (a) The photocurrent density vs. applied potential $\left(\mathrm{ph}_{\mathrm{ph}}-V\right)$ curves of $\mathrm{CuWO}_{4}$ and $\mathrm{CuWO}_{4} / \mathrm{IrCo}(9: 1)$-Pi with varied deposition cycles. (b)The corresponding $J_{\text {dark }}-V$ and $J_{\text {total }}-V$ curves of $\mathrm{CuWO}_{4}$ and $\mathrm{CuWO}_{4} / \mathrm{IrCo}(9: 1)$-Pi with varied deposition cycles, Figure S4: (a) $J_{\text {dark }}-V$ and $J_{\text {total }}-V$ curves of $\mathrm{CuWO}_{4}$ and $\mathrm{CuWO}_{4} / \mathrm{IrCo}$-Pi with varied $R_{\text {Ir-to-Co }}$. (b) The enlarged $J_{\text {dark }}-V$ curves of $\mathrm{CuWO} 4$ and $\mathrm{CuWO}_{4} / \mathrm{IrCo}-\mathrm{Pi}$ within the potential range from $1.40 \mathrm{~V}$ to $1.80 \mathrm{~V}$ vs. RHE. (c) Current density-time responses of $\mathrm{CuWO}_{4}$ at $1.23 \mathrm{~V}$ vs. RHE under continuous illumination, Figure S5: (a) Transient photocurrent density curves for $\mathrm{CuWO}_{4}$ and $\mathrm{CuWO}_{4} / \mathrm{IrCo}(9: 1)$-Pi at $1.05 \mathrm{~V}$ vs. RHE for multiple light-on/light-off cycles.(b) $J_{\mathrm{ph}^{-}} V$ curves of $\mathrm{CuWO}_{4}$ and $\mathrm{CuWO}_{4} / \mathrm{IrCo}(9: 1)$-Pi obtained in the presence or absence of hole scavenger $\left(0.1 \mathrm{M} \mathrm{Na}_{2} \mathrm{SO}_{3}\right)$, Table S1: The nominal and actual $R_{\text {Ir-to-Co }}$ for $\mathrm{CuWO}_{4} / \mathrm{IrCo}$-Pi samples, Table S2: The fitting values for $R_{\mathrm{S}}, R_{\mathrm{ct}}$ and CPE using the equivalent circuit displayed in the inset of Figure $5 \mathrm{~d}$.

Author Contributions: Conceptualization, Methodology, Formal analysis, Writing-original draft preparation, C.L. Conceptualization, Writing - review and editing, Supervision, P.D. All authors have read and agreed to the published version of the manuscript.

Funding: This research was funded by National Natural Science Foundation of China, grant number (51672017, 51872015).

Conflicts of Interest: The authors declare no conflict of interest.

\section{References}

1. Grätzel, M. Photoelectrochemical cells. Nature 2001, 414, 338-344. [CrossRef] [PubMed]

2. Walter, M.G.; Warren, E.L.; McKone, J.R.; Boettcher, S.W.; Mi, Q.; Santori, E.A.; Lewis, N.S. Solar water splitting cells. Chem. Rev. 2010, 110, 6446-6473. [CrossRef] [PubMed]

3. Hurst, J.K. In pursuit of water oxidation catalysts for solar fuel production. Science 2010, 328, 315-316. [CrossRef] [PubMed]

4. Fujishima, A.; Honda, K. Electrochemical photolysis of water at a semiconductor electrode. Nature 1972, 238, 37-38. [CrossRef] [PubMed]

5. Steinmiller, E.M.P.; Choi, K.S. Photochemical deposition of cobalt-based oxygen evolving catalyst on a semiconductor photoanode for solar oxygen production. Proc. Natl. Acad. Sci. USA 2009, 106, 20633-20636. [CrossRef]

6. Kang, Z.; Si, H.; Zhang, S.; Wu, J.; Sun, Y.; Liao, Q.; Zhang, Z.; Zhang, Y. Interface engineering for modulation of charge carrier behavior in $\mathrm{ZnO}$ photoelectrochemical water splitting. Adv. Funct. Mat. 2019, 29, 1808032-1808050. [CrossRef] 
7. Su, J.; Feng, X.; Sloppy, J.D.; Guo, L.; Grimes, C.A. Vertically aligned $\mathrm{WO}_{3}$ nanowire arrays grown directly on transparent conducting oxide coated glass: Synthesis and photoelectrochemical properties. Nano Lett. 2011, 11, 203-208. [CrossRef]

8. Jin, T.; Diao, P.; Xu, D.; Wu, Q. High-aspect-ratio $\mathrm{WO}_{3}$ nanoneedles modified with nickel-borate for efficient photoelectrochemical water oxidation. Electrochim. Acta 2013, 114, 271-277. [CrossRef]

9. Hu, D.; Diao, P.; $\mathrm{Xu}, \mathrm{D}$.; $\mathrm{Wu}, \mathrm{Q}$. Gold $/ \mathrm{WO}_{3}$ nanocomposite photoanodes for plasmonic solar water splitting. Nano Res. 2016, 9, 1735-1751. [CrossRef]

10. Jin, T.; Diao, P.; Wu, Q.; Xu, D.; Hu, D.; Xie, Y.; Zhang, M. $\mathrm{WO}_{3}$ nanoneedles $/ \alpha-\mathrm{Fe}_{2} \mathrm{O}_{3} /$ cobalt phosphate composite photoanode for efficient photoelectrochemical water splitting. Appl. Catal. B: Environ. 2014, 148-149, 304-310. [CrossRef]

11. Wu, Q.; Xu, D.; Xue, N.; Liu, T.; Xiang, M.; Diao, P. Photo-catalyzed surface hydrolysis of iridium(iii) ions on semiconductors: A facile method for the preparation of semiconductor/IrOx composite photoanodes toward oxygen evolution reaction. Phys. Chem. Chem. Phys. 2017, 19, 145-154. [CrossRef] [PubMed]

12. Xi, L.; Lange, K.M. Surface modification of hematite photoanodes for improvement of photoelectrochemical performance. Catalysts 2018, 8, 497-511. [CrossRef]

13. Fu, Y.; Dong, C.L.; Zhou, W.; Lu, Y.R.; Huang, Y.C.; Liu, Y.; Guo, P.; Zhao, L.; Chou, W.C.; Shen, S. A ternary nanostructured $\alpha-\mathrm{Fe}_{2} \mathrm{O}_{3} / \mathrm{Au} / \mathrm{TiO}_{2}$ photoanode with reconstructed interfaces for efficient photoelectrocatalytic water splitting. Appl. Catal. B Environ. 2020, 260, 118206-118214. [CrossRef]

14. Butler, M.A. Photoelectrolysis and physical properties of the semiconducting electrode $\mathrm{WO}_{3}$. J. Appl. Phys. 1977, 48, 1914-1920. [CrossRef]

15. Liu, X.; Wang, F.; Wang, Q. Nanostructure-based $\mathrm{WO}_{3}$ photoanodes for photoelectrochemical water splitting. Phys. Chem. Chem. Phys. 2012, 14, 7894-7911. [CrossRef] [PubMed]

16. Cho, I.S.; Kwak, C.H.; Kim, D.W.; Lee, S.; Hong, K.S. Photophysical, photoelectrochemical, and photocatalytic properties of novel $\mathrm{SnWO}_{4}$ oxide semiconductors with narrow band gaps. J. Phys. Chem. C 2009, 113, 10647-10653. [CrossRef]

17. Kölbach, M.; Pereira, I.J.; Harbauer, K.; Plate, P.; Höflich, K.; Berglund, S.P.; Friedrich, D.; van de Krol, R.; Abdi, F.F. Revealing the performance-limiting factors in $\alpha-\mathrm{SnWO}_{4}$ photoanodes for solar water splitting. Chem. Mat. 2018, 30, 8322-8331. [CrossRef]

18. Ke, J.; Adnan Younis, M.; Kong, Y.; Zhou, H.; Liu, J.; Lei, L.; Hou, Y. Nanostructured ternary metal tungstate-based photocatalysts for environmental purification and solar water splitting: A review. Nano-Micro Lett. 2018, 10, 69-95. [CrossRef]

19. Yourey, J.E.; Bartlett, B.M. Electrochemical deposition and photoelectrochemistry of $\mathrm{CuWO}_{4}$, a promising photoanode for water oxidation. J. Mat. Chem. 2011, 21, 7651-7660. [CrossRef]

20. Hill, J.C.; Choi, K.S. Synthesis and characterization of high surface area $\mathrm{CuWO}_{4}$ and $\mathrm{Bi}_{2} \mathrm{WO}_{6}$ electrodes for use as photoanodes for solar water oxidation. J. Mater. Chem. A 2013, 1, 5006-5014. [CrossRef]

21. Yourey, J.E.; Pyper, K.J.; Kurtz, J.B.; Bartlett, B.M. Chemical stability of $\mathrm{CuWO}_{4}$ for photoelectrochemical water oxidation. J. Phys. Chem. C 2013, 117, 8708-8718. [CrossRef]

22. Pyper, K.J.; Yourey, J.E.; Bartlett, B.M. Reactivity of $\mathrm{CuWO}_{4}$ in photoelectrochemical water oxidation is dictated by a midgap electronic state. J. Phys. Chem. C 2013, 117, 24726-24732. [CrossRef]

23. Gao, Y.; Zandi, O.; Hamann, T.W. Atomic layer stack deposition-annealing synthesis of CuWO . J. Mater. Chem. A 2016, 4, 2826-2830. [CrossRef]

24. Hu, D.; Diao, P.; Xu, D.; Xia, M.; Gu, Y.; Wu, Q.; Li, C.; Yang, S. Copper(ii) tungstate nanoflake array films: Sacrificial template synthesis, hydrogen treatment, and their application as photoanodes in solar water splitting. Nanoscale 2016, 8, 5892-5901. [CrossRef]

25. Ye, W.; Chen, F.; Zhao, F.; Han, N.; Li, Y. CuWO 4 nanoflake array-based single-junction and heterojunction photoanodes for photoelectrochemical water oxidation. ACS Appl. Mat. Interfaces 2016, 8, 9211-9217. [CrossRef]

26. Davi, M.; Mann, M.; Ma, Z.; Schrader, F.; Drichel, A.; Budnyk, S.; Rokicinska, A.; Kustrowski, P.; Dronskowski, R.; Slabon, A. An MnNCN-derived electrocatalyst for $\mathrm{CuWO}_{4}$ photoanodes. Langmuir 2018, 34, 3845-3852. [CrossRef]

27. Lhermitte, C.R.; Bartlett, B.M. Advancing the chemistry of $\mathrm{CuWO}_{4}$ for photoelectrochemical water oxidation. Acc. Chem. Res. 2016, 49, 1121-1129. [CrossRef] 
28. Yang, J.; Li, C.; Diao, P. Molybdenum doped $\mathrm{CuWO}_{4}$ nanoflake array films as an efficient photoanode for solar water splitting. Electrochim. Acta 2019, 308, 195-205. [CrossRef]

29. Li, C.; Diao, P. Fluorine doped copper tungsten nanoflakes with enhanced charge separation for efficient photoelectrochemical water oxidation. Electrochim. Acta 2020, 352, 136471-136479. [CrossRef]

30. Peng, B.; Xia, M.; Li, C.; Yue, C.; Diao, P. Network structured $\mathrm{CuWO}_{4} / \mathrm{BiVO}_{4} / \mathrm{Co}-\mathrm{Pi}$ nanocomposite for solar water splitting. Catalysts 2018, 8, 663-671. [CrossRef]

31. Lo Vecchio, C.; Trocino, S.; Campagna Zignani, S.; Baglio, V.; Carbone, A.; Díez García, M.I.; Contreras, M.; Gómez, R.; Aricò, A.S. Enhanced photoelectrochemical water splitting at hematite photoanodes by effect of a NiFe-oxide co-catalyst. Catalysts 2020, 10, 525-541. [CrossRef]

32. Hamann, T. Electron dynamics at the $\mathrm{CuWO}_{4} /$ electrocatalyst interface for photoelectrochemical water oxidation. In Proceedings of the Processes at the Semiconductor Solution Interface, 235th ECS Meeting, Dallas, TX, USA, 26-30 May 2019; p. 1226. [CrossRef]

33. Xu, X.T.; Pan, L.; Zhang, X.; Wang, L.; Zou, J.J. Rational design and construction of cocatalysts for semiconductor-based photo-electrochemical oxygen evolution: A comprehensive review. Adv. Sci. 2019, 6, 1801505-1801539. [CrossRef]

34. Irshad, A.; Munichandraiah, N. High catalytic activity of amorphous Ir-Pi for oxygen evolution reaction. ACS Appl. Mat. Interfaces 2015, 7, 15765-15776. [CrossRef] [PubMed]

35. Wang, Z.; Lin, Z.; Diao, P. Hybrids of iridium-cobalt phosphates as a highly efficient electrocatalyst for the oxygen evolution reaction in neutral solution. Chem. Commun. 2019, 55, 3000-3003. [CrossRef]

36. Kanan, M.W.; Nocera, D.G. In situ formation of an oxygen-evolving catalyst in neutral water containing phosphate and $\mathrm{Co}^{2+}$. Science 2008, 321, 1072-1075. [CrossRef]

37. Jeon, T.H.; Choi, W.; Park, H. Cobalt-phosphate complexes catalyze the photoelectrochemical water oxidation of $\mathrm{BiVO}_{4}$ electrodes. Phys. Chem. Chem. Phys. 2011, 13, 21392-21401. [CrossRef]

38. Abdi, F.F.; van de Krol, R. Nature and light dependence of bulk recombination in Co-Pi-catalyzed $\mathrm{BiVO}_{4}$ photoanodes. J. Phys. Chem. C 2012, 116, 9398-9404. [CrossRef]

39. Nam, K.M.; Cheon, E.A.; Shin, W.J.; Bard, A.J. Improved photoelectrochemical water oxidation by the $\mathrm{WO}_{3} / \mathrm{CuWO}_{4}$ composite with a manganese phosphate electrocatalyst. Langmuir 2015, 31, 10897-10903. [CrossRef]

40. Chen, S.; Hossain, M.N.; Chen, A. Significant enhancement of the photoelectrochemical activity of $\mathrm{CuWO}_{4}$ by using a cobalt phosphate nanoscale thin film. ChemElectroChem 2018, 5, 523-530. [CrossRef]

41. Xiong, X.; Fan, L.; Chen, G.; Wang, Y.; Wu, C.; Chen, D.; Lin, Y.; Li, T.; Fu, S.; Ren, S. Boosting water oxidation performance of $\mathrm{CuWO}_{4}$ photoanode by surface modification of nickel phosphate. Electrochim. Acta 2019, 328, 135125-135133. [CrossRef]

42. Tafalla, D. Kinetic approach to the photocurrent transients in water photoelectrolysis at n- $\mathrm{TiO}_{2}$ electrodes. J. Electrochem. Soc. 1990, 137, 1810-1815. [CrossRef]

43. Hagfeldt, A.; Lindström, H.; Södergren, S.; Lindquist, S.E. Photoelectrochemical studies of colloidal TiO films: The effect of oxygen studied by photocurrent transients. J. Electroanal. Chem. 1995, 381, 39-46. [CrossRef]

44. Le Formal, F.; Sivula, K.; Grätzel, M. The transient photocurrent and photovoltage behavior of a hematite photoanode under working conditions and the influence of surface treatments. J. Phys. Chem. C 2012, 116, 26707-26720. [CrossRef]

45. Kim, D.W.; Riha, S.C.; DeMarco, E.J.; Martinson, A.B.F.; Farha, O.K.; Hupp, J.T. Greenlighting photoelectrochemical oxidation of water by iron oxide. ACS Nano 2014, 8, 12199-12207. [CrossRef] [PubMed]

46. Zhang, $\mathrm{H}$.; Cheng, C. Three-dimensional $\mathrm{FTO} / \mathrm{TiO}_{2} / \mathrm{BiVO}_{4}$ composite inverse opals photoanode with excellent photoelectrochemical performance. ACS Energy Lett. 2017, 2, 813-821. [CrossRef]

47. Gao, L.; Li, F.; Hu, H.; Long, X.; Xu, N.; Hu, Y.; Wei, S.; Wang, C.; Ma, J.; Jin, J. Dual modification of a BiVO photoanode for enhanced photoelectrochemical performance. ChemSusChem 2018, 11, 2502-2509. [CrossRef]

48. Gao, Y.; Hamann, T.W. Quantitative hole collection for photoelectrochemical water oxidation with $\mathrm{CuWO}_{4}$. Chem. Commun. 2017, 53, 1285-1288. [CrossRef]

49. Klahr, B.; Gimenez, S.; Fabregat-Santiago, F.; Bisquert, J.; Hamann, T.W. Photoelectrochemical and impedance spectroscopic investigation of water oxidation with "Co-Pi"-coated hematite electrodes. J. Am. Chem. Soc. 2012, 134, 16693-16700. [CrossRef] 
50. Klahr, B.; Giménez, S.; Fabregat-Santiago, F.; Bisquert, J.; Hamann, T.W. Electrochemical and photoelectrochemical investigation of water oxidation with hematite electrodes. Energy Environ. Sci. 2012, 5, 7626-7636. [CrossRef]

51. Chen, Z.; Jaramillo, T.F.; Deutsch, T.G.; Kleiman-Shwarsctein, A.; Forman, A.J.; Gaillard, N.; Garland, R.; Takanabe, K.; Heske, C.; Sunkara, M.; et al. Accelerating materials development for photoelectrochemical hydrogen production: Standards for methods, definitions, and reporting protocols. J. Mat. Res. 2011, 25, 3-16. [CrossRef]

(C) 2020 by the authors. Licensee MDPI, Basel, Switzerland. This article is an open access article distributed under the terms and conditions of the Creative Commons Attribution (CC BY) license (http://creativecommons.org/licenses/by/4.0/). 